\title{
Entrevista com Ana Taglianetti, Daniel Souza e Fernando Bustamante sobre o Projeto Teatro Musical na UFMG
}

Fausto Borém (UFMG, Belo Horizonte)

fborem@ufmg.br

Palavras-chave: teatro; musicais; música popular; canto; belting; Broadway; Disney.

Interview with Ana Taglianetti, Daniel Souza and Fernando Bustamante about the Teatro Musical Project at UFMG

Keywords: theatre; musicals; popular music; singing; belting; Broadway; Disney.

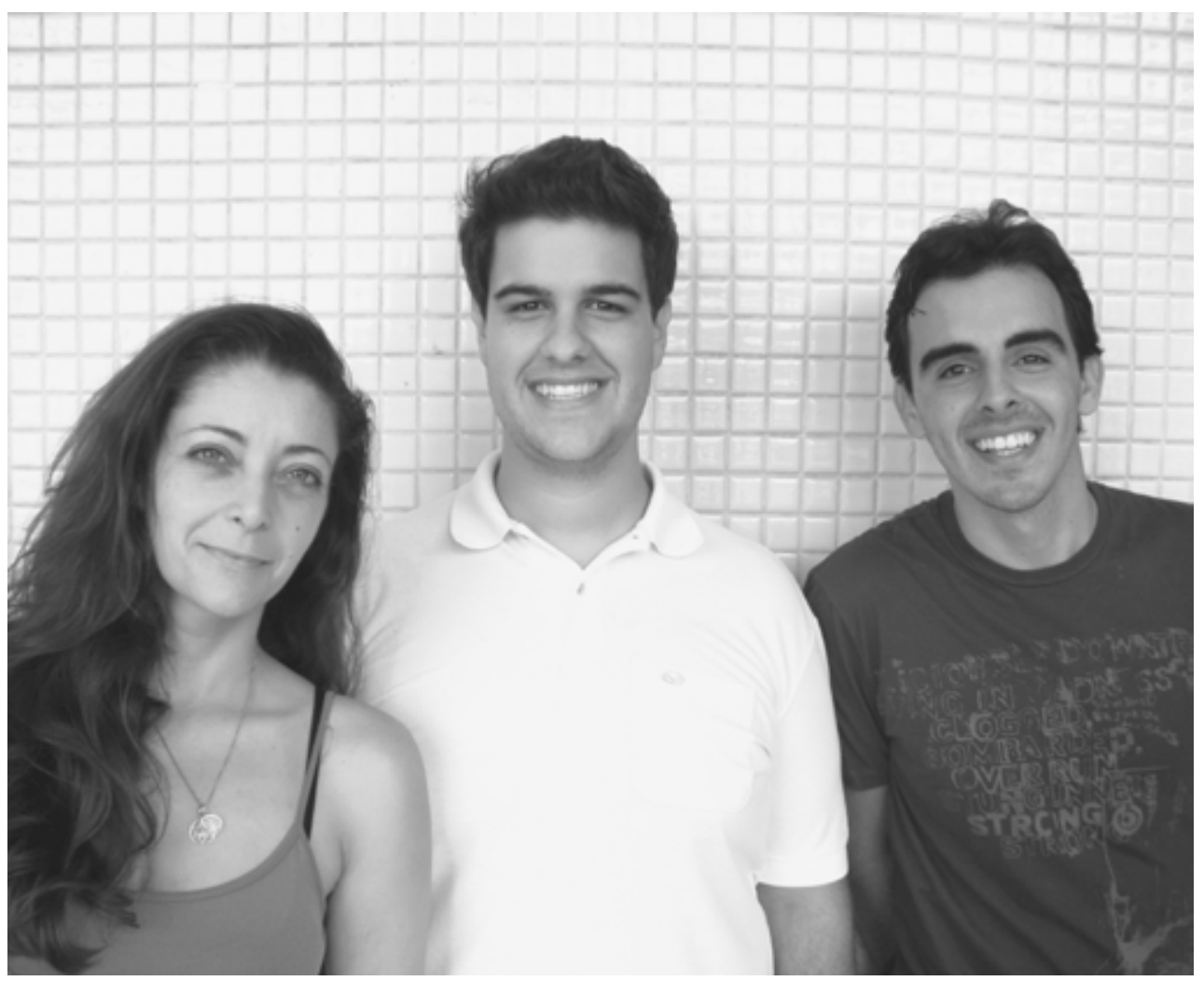

Ana Taglianetti e Daniel Souza (Monitores do Projeto Teatro Musical na UFMG)

e Fernando Bustamante (Diretor Convidado do Projeto Teatro Musical na UFMG) 
1 - FAUSTO BORÉM: Primeiro, gostaria que vocês falassem um pouco sobre os musicais, este gênero de tanto sucesso e ainda tão pouco estudado academicamente, no contexto da história da música e principais centros de produção.

DANIEL SOUZA: A música tem um papel primordial nos espetáculos teatrais desde os tempos mais remotos. Na Grécia Antiga, o canto era comumente utilizado e Aristóteles já se referia à música como um dos seis elementos fundamentais das tragédias gregas. Com o passar dos tempos, na Idade Média, podemos observar também os dramas litúrgicos ou religiosos e outras representações, como jograis, saltimbancos e malabaristas que se utilizavam da linguagem musical e dramática na mesma representação. No renascimento e barroco, houve uma grande propagação de gêneros teatrais cantados, culminando no surgimento das primeiras óperas. Com a chegada do século XIX, a ópera, a opereta e o cabaret tornam-se cada vez mais criativos e mais populares. Na Broadway, em Nova Yorque, EUA, o teatro musical ganhou sua versão mais próxima do que conhecemos hoje. Mas outros centros artísticos no mundo têm também grande importância na produção de musicais, como o West End, em Londres e diversos teatros franceses.

\section{2 - FAUSTO BORÉM: Podem citar alguns dos principais} compositores e letristas/roteiristas do teatro musical?

DANIEL SOUZA: No teatro musical internacional, podemos destacar compositores como Jerome Kern, Cole Porter, Irving Berlim, George e Ira Gershwin, Vincent Youmans, Alan Jay Lerner, Leonard Bernstein e Andrew Lloyd Webber, Cole Poter, Richard Rodgers Hammerstein, Frederick Loewe, Stephen Sondheim (que também era um grande letrista), John Kander, Fred Ebb, Claude-Michel Schoenberg, Elton John (por seus trabalhos para a Disney Theatrical), Marvin Hamlisch, Stephen Schwartz, Jonathan Larson, entre muitos outros. Entres os letristas e roteiristas, não podemos esquecer nomes como Oscar Hammerstein II, o próprio compositor Sondheim, Tim Rice, Jerry Herman, também compositor e Alain Boublil.

ANA TAGLIANETTI: Como veem, são muitos! Mas a gente sempre tem os nossos preferidos... Rodgers e Hammerstein, Shoenberg e Boubil, Stephen Sondheim são os meus eleitos!

FERNANDO BUSTAMANTE: Já o teatro musical brasileiro, desde o final do século XIX, também teve grandes compositores. Destaco Chiquinha Gonzaga (grande referência para o Teatro de Revista), Carlos Gomes, Ary Barroso e Assis Valente, que também musicaram peças e revistas teatrais. A partir da década de 1960, Chico Buarque, Tom Jobim, Vinicius de Moraes e Tim Rescala estão entre os mais importantes compositores do gênero no Brasil.
3 - FAUSTO BORÉM: Historicamente, a ópera acompanhou a estética de cada época (barroco, classicismo, romantismo, expressionismo etc.), com também valorizou as expressões culturais fortes de alguns países, como a dança na França, o bel canto na Itália e a literatura na Alemanha. Há um paralelo na história dos musicais?

DANIEL SOUZA: A história dos musicais é bem mais recente do que a história da ópera, mas a evolução do gênero a partir dela, de outras expressões musicais e da dança é evidente. A opereta e o cabaret foram os grandes inspiradores dos primeiros musicais e a linha que separa um gênero do outro nos primórdios do teatro musical é, muitas vezes, tênue. Alguns exemplos são os musicais Jesus Cristo Superstar e Hair, fortemente enraizados no pop e no rock. Outros, como Dreamgirls, Raisin, Purlie, The Wiz, Ragtime e A Cor Púrpura trazem uma grande influência da cultura norte-americana afro-descendente. Na França, a literatura e as guerras inspiraram criações como Les Misérables e Miss Saigon. Em Londres, Andrew Lloyd Webber inspirou-se na literatura para as composições de Cats e 0 Fantasma da Ópera e na vida de Eva Perón, da Argentina, para a composição do musical Evita. Óperas do século XIX, como Madame Butterfly, La Bohème e La Traviata também foram inspiradoras de enredos de musicais, como em Miss Saigon, Rent e Moulin Rouge, este último um longa-metragem de 2001 que ainda não recebeu versão para o palco. Mas, certamente, uma das mais fortes expressões culturais que influenciaram a produção de musicais foi o cinema e suas grandes produções, que ora reproduziam um grande musical dos palcos, ora inspiravam outros que fariam temporada em teatros do mundo inteiro. A própria Disney transformou alguns de seus grandes clássicos de animação e longa-metragem, como $A$ Bela e a Fera, 0 Rei Leão, A Pequena Sereia e Mary Poppins, em musicais de sucesso no palco. Devemos citar os musicais criados em cima de grandes coletâneas de canções de sucesso do século XX, como Mamma Mia!, inspirado nas músicas do grupo Abba, We will rock you com músicas do grupo Queen, Movin'Out, baseado nas melodias de Billy Joel, Good Vibrations, com músicas dos Beach Boys e All Shook Up, baseado em sucessos de Elvis Presley.

4 - FAUSTO BORÉM: Quais são as diferenças estéticas e mercadológicas entre os musicais para adultos e para crianças?

FERNANDO BUSTAMANTE: Historicamente, existe um preconceito sobre a montagem de espetáculos para crianças, muitas vezes considerada uma arte menor. Entretanto, os artistas que investem nesse segmento têm mostrado a importância de uma boa equipe de criação em um espetáculo, seja ele destinado ao público adulto ou infantil. Deve haver uma preocupação com todos os elementos que compõem a encenação (qualidade do texto, música, cenário, figurino, iluminação, elenco de atores, cantores e bailarinos etc.), seja qual for o gênero da peça. Portanto, as diferenças estéticas estão relacionadas aos mecanismos utilizados para articular esses elementos na encenação. Em termos de mercado, podemos afirmar que existe uma forte 
tendência de, nos espetáculos infantis, criar um interesse também nos pais e acompanhantes presentes na plateia. Não acontece o inverso no musical adulto.

5 - FAUSTO BORÉM: No Brasil, e em Belo Horizonte, especificamente, houve um processo continuado de desenvolvimento dos musicais? Quais são as perspectivas?

FERNANDO BUSTAMANTE: 0 Teatro de Revista é a maior referência do teatro musical no Brasil. Depois da sua decadência na década de 1950, o gênero retorna aos palcos em algumas adaptações do modelo da Broadway, a partir da década de 1960 . No período do regime militar vimos seu recrudescimento pela ação da censura oficial em montagens como as de Chico Buarque (Roda Viva, Gota d'Água e pera do Malandro). Ainda assim, o gênero parecia não ter o mesmo espaço na preferência do público, como ocorreu no final do século XIX.

No início do século XXI, espetáculos voltam a importar 0 modelo americano da Broadway e recebem versões brasileiras com o trabalho de Cláudio Botelho e Charles Möeller. A precisão técnica e o virtuosismo chamam a atenção do público e a demanda por profissionais para compor 0 elenco destes espetáculos têm contribuído para o desenvolvimento dos musicais no Brasil.

Em Belo Horizonte, destacamos o trabalho do diretor Pedro Paulo Cava em montagens musicais adultas e infantis a partir da década de 1970. Outros nomes do teatro mineiro contribuíram para fomentar o desenvolvimento do gênero no estado. 0 Grupo Galpão, Grupo Ponto de Partida, Ernani Maleta, Fernando Muzzi, Maurício Tizumba são alguns deles.

6 - FAUSTO BORÉM: E você próprio, Fernando [Bustamante], não podemos esquecer, que tem desenvolvido aqui em Belo Horizonte um trabalho referencial no teatro musical, com prêmiações como diretor, produtor, ator, preparador corporal, entre outras. Dá para se perceber que há um sopro novo na cidade em torno da produção e aprendizagem do gênero musical. Você Ana, que fundou a principal escola de preparação de cantores-atores para musicais no país [a Casa de Artes OperÁria, em São Paulo] e tem vasta experiência no exterior com o canto lírico e o belting, mudou-se para a cidade há dois anos. E você, Daniel [Souza], que trabalhou na Disney dos EUA e graduou-se em regência orquestral, concentra boa parte de suas atividades nesta área. Como surgiu a ideia de iniciar um núcleo de produção de musicais, integrando o ensino do teatro, música e dança na universidade brasileira?

ANA TAGLIANETTI: Tudo começou espontaneamente, a partir da disposição do maestro Daniel Souza e da soprano Fabiola Protzner de criarem um espetáculo de highlights de musicais com os alunos do Bacharelado da Escola de Música da UFMG. Isso foi em 2008, ano em que ingressei na UFMG e me mudei de São Paulo para BH. Como souberam da minha longa experiência com esta linguagem cê- nica na Casa de Artes OperÁria ${ }^{1}$, em São Paulo e da minha decisão de morar em Belo Horizonte, acabaram por me convidar para desenvolver com eles um projeto de montagem, que acabou intitulado Uma noite na Broadway. Este projeto frutificou, se tornou o Projeto Teatro Musical na UFMG, foi apresentado em várias cidades de Minas Gerais e, no ano seguinte, acabamos encenando o Uma noite na Broadway II. 0 projeto se desdobrou em duas frentes, este que continuei coordenando e outro, com o diretor Fernando Bustamante, que foi convidado para coordenar a montagem de A Pequena sereia. Ambos projetos contaram praticamente com o mesmo elenco. Em 2010, começaremos a encenação do projeto Uma noite na Broadway III.

Ainda do ponto de vista de inserção dos musicais na universidade, devo dizer que a UFMG é a primeira universidade brasileira a incluir este tópico em um currículo de um curso superior de música. $E$ isto só foi possivel com o apoio do Professor Lucas Bretas, como Diretor da Escola de Música da UFMG e como Professor que implantou esta disciplina no currículo. Para 2011, temos a previsão da vinda do maestro e Doutor em Música norte-americano Barry Kolman, com larga experiência no repertório sinfônico e de musicais, como pesquisador e professor visitante da Fullbright.

7 - FAUSTO BORÉM: Como se dá a seleção dos elencos e quais são os requisitos para participar do projeto. Há preferências por tipos de voz, tipos físicos, personalidades etc.? Há um predomínio de atores que cantam e dançam, de músicos que atuam e dançam ou de bailarinos que atuam e cantam?

ANA TAGLIANETTI: A seleção de elenco para um musical de grande porte, especialmente para os "importados enlatados", parte de alguns pré-requisitos. Para um determinado papel, o diretor procura, por exemplo, uma jovem de 20 a 24 anos, magra e negra, que seja cantora e bailarina profissional. Se for isso que ele precisa para aquele determinado papel, não adianta artistas com outros perfis desejarem fazer o teste, estão claras as demandas do diretor. $\mathrm{Na}$ maioria das audições, quando as provas são divulgadas, já se sabe precisamente o que se espera para os papéis, inclusive a extensão e tipo vocal. Portanto, com as partituras do repertório em mãos, um cantor pode, por exemplo, saber se consegue atingir os limites melódicos inferior e superior das canções, com a intensidade e qualidade necessárias. Costuma ser tudo muito específico.

No caso de produções menores, ou montagens originais, ou de textos brasileiros, isso pode ser diferente. As audições podem ter um caráter mais aberto, mais livre. Em geral, os candidatos passam por uma pré-seleção de currículo e, então, são chamados - ou não! - para serem ouvidos, e isso acontece em quase todos os casos. No caso do Projeto Teatro Musical na UFMG, a coisa é bem diferente. Estamos selecionando elencos para projetos educativos. Nossos testes não são eliminatórios, mas sim classificatórios. Qualquer um pode participar, guardadas as dimensões do que tem para oferecer ao artista em formação. 
FERNANDO BUSTAMANTE: Gostaria de acrescentar que, não raro, o diretor de musicais enfrenta imprevistos - como doença, acidentes, viagens etc.- que acarretam a substituição de membros do elenco. Por isso mesmo, é comum, e mais seguro, a preparação de dois elencos: o principal e o substituto ou alternante. Só para dar um exemplo, na estreia da versão estendida de $A$ Pequena sereia (inspirada no repertório musical e roteiro da Broadway) em Minas Gerais, tínhamos cerca de 50 pessoas no elenco, entre cantores-atores, bailarinos, músicos de orquestra e pessoal de iluminação e de gerenciamento de palco. Por outro lado, a flexibilidade brasileira ajuda nestas horas. Só para dar um exemplo, na versão abreviada de $A$ Pequena sereia (inspirada no texto original de Hans Christian Andersen e músicas do filme da Disney) minha atriz-cantora Jai Baptista faz três papéis com perfis diferentes, o que exige muita agilidade na troca de figurinos e caráter das falas e canções: uma das irmãs-sereias, a noiva que pretere Ariel e a gaivota-macho Sabidão. Mas o improviso tem também o seu lugar: quando a Jai, que é negra, faz o papel de Sabidão e entoa um agudo áspero e desafinado, o siri Sebastião faz um aparte - "Cala a boca, Elza Soares!", que se tornou um bordão que só pode ser apreciado no Brasil.

8 - FAUSTO BORÉM: Uma questão delicada na relação diretor versus elenco: como se dá o processo de cortes no elenco por insuficiência na expressão ou demandas do personagem? Como o diretor aborda a questão da competição e da humildade entre os membros do elenco?

FERNANDO BUSTAMANTE: Normalmente, fazemos audições para avaliar as condições técnicas e o perfil de cada integrante do elenco a ser escolhido. Entretanto, se houver a necessidade de cortes, "diplomacia" é a palavrachave para resolver a questão. Vivemos num meio cheio de vaidades e é preciso medir as palavras na hora de tomar qualquer atitude. Acredito que a "competição" deve ocorrer somente no momento das audições. Durante os ensaios, é essencial ter consciência da importância do coletivo e do trabalho colaborativo de cada integrante.

DANIEL SOUZA: A modificação de um elenco durante a construção ou durante a temporada de apresentações de um espetáculo é sempre um processo complicado. As decisões devem levar em consideração os prós e os contras no caso de cortes ou trocas de papéis no elenco. Às vezes, o corte é necessário e até indispensável, mesmo com as rupturas que causa no trabalho ou nos relacionamentos dentro do próprio elenco. Porém, é sempre importante lembrar que as questões pessoais devem ser colocadas de lado para que prevaleça o profissionalismo.

ANA TAGLIANETTI: Na minha experiência, vi isso acontecer raras vezes, uma vez que no próprio processo de seleção os escolhidos costumam ser eleitos por serem capazes de dar conta do recado.
9 - FAUSTO BORÉM: Poderiam situar o Projeto Teatro Musical no contexto brasileiro, tanto em relação às praças consolidadas de São Paulo e Rio de Janeiro, quanto a outros possíveis pólos emergentes?

ANA TAGLIANETTI: Sem dúvida nenhuma, o Projeto Teatro Musical na UFMG possibilitou a descoberta de incríveis talentos mineiros para o teatro musical. E agora, com tantos jovens artistas de Belo Horizonte preparados para 0 trabalho com essa linguagem, essa cidade se torna um caldeirão de possibilidades maravilhosas para que os diretores locais possam contar com estes artistas, agora mais preparados para lidar com a linguagem do musical. Os talentos que descobrimos aqui são de alta qualidade, e acredito que Belo Horizonte tem tudo para se tornar a próxima cidade brasileira, depois de Rio de Janeiro e São Paulo, a entrar no circuito dos grandes musicais. Basta que os produtores locais queiram investir em montagens e que os atores queiram permanecer em $\mathrm{BH}$ e trabalhar localmente. Há uma grande tradição do canto em Minas Gerais, e este parece um bom momento para que o estado pare de exportar seus melhores talentos. Como educadora com quase 20 anos de experiência no ensino de musicais, já formei centenas de artistas, e confesso que poucas vezes me deparei com o nível dos jovens talentos para o musical que encontrei aqui.

10 - FAUSTO BORÉM: Quais as diferenças entre o musical norte-americano e o teatro de revistas brasileiro? Porque o primeiro se tornou um mercado milionário e 0 segundo entrou em decadência após uma época de ouro?

FERNANDO BUSTAMANTE: 0 teatro de revista retratou a sociedade da época, tornou mais acessivel o gênero ao grande público e contribuiu para difundir modos e costumes através da linguagem composta pela crítica apimentada e personagens alegóricos. Entretanto, o apelo para o escracho e para o nu explícito, em detrimento da comicidade, foi o grande responsável pela sua decadência. Já o musical norte-americano apostou na versatilidade de estilos musicais, no apuro técnico e na miscigenação de estilos e raças. Esses fatores reunidos foram essenciais para o desenvolvimento de um mercado milionário do entretenimento.

11 - FAUSTO BORÉM: Quais são os desafios de dirigir cenicamente um musical?

FERNANDO BUSTAMANTE: É muito importante para o diretor/encenador esclarecer para todos os membros da equipe de criação que a "música", nos musicais, torna-se um adjetivo do substantivo teatro, ou seja, tudo deve ser planejado em função da cena. Muitas vezes, a canção ou trecho instrumental pode ser uma verdadeira obra prima, mas pode não permitir a intenção ou expressão do personagem. Isso se aplica a todos os outros elementos cênicos. Outros fatores importantes são o acabamento, 0 planejamento das transições, entradas e saídas de cenário e elenco, as coreografias etc. Cada detalhe é importante para compor um grande espetáculo. 


\section{2- FAUSTO BORÉM: Quais são os desafios de se fazer} um musical com música ao vivo?

DANIEL SOUZA: Existem vários desafios para se fazer um musical ao vivo, que geralmente dura cerca de 140 minutos. 0 primeiro e maior deles é o financeiro: além dos cantores/atores, é preciso contratar os músicos para a formação instrumental desejada, além de, minimamente, técnicos de som. 0 ideal é que todo espetáculo de teatro musical seja microfonado (cantores, instrumentistas e atores), para se obter um melhor equilibrio sonoro e evitar um grande desgaste das vozes. Em caso de temporadas de pelo menos quatro apresentações por semana isso se torna essencial para a saúde vocal do ator/cantor, para se obter melhores resultados na performance. Por outro lado, a formação instrumental de um musical geralmente é reduzida por questões financeiras ou de espaço. 0 próprio equipamento de sonorização é uma questão financeira delicada: microfones, caixas e mesas de som especificas costumam elevar muito os custos em uma produção. A própria necessidade de economizar acaba atrapalhando, pois costuma-se ensaiar sem os equipamentos de som para diminuir custos, o que, depois, gera problemas para equilibrar solistas, coro e orquestra no palco.

13 - FAUSTO BORÉM: Quais são os desafios de tradução dos textos originais para o português?

FERNANDO BUSTAMANTE: Traduzir é muito diferente de "versionar" uma música, o que é o ideal. Na versão, existe a preocupação em aproximar a sonoridade das palavras originais. 0 sentido das frases tem que ser mantido. 0 nosso vocabulário possui palavras muito extensas, especialmente em relação ao inglês, e isso dificulta ainda mais o trabalho. Outro fator que deve ser considerado é o contexto onde os textos e as músicas originais estão inseridos. Uma piada em inglês pode não funcionar em português, se não for adaptada à realidade brasileira. Referências a gírias, costumes e hábitos na cultura da língua original devem ser cuidadosamente avaliadas e adaptadas para fazerem sentido no português brasileiro.

14 - FAUSTO BORÉM: Podem falar sobre as diferenças entre as técnicas vocais do musical, da música popular e da ópera? Há uma relação entre técnicas vocais e clareza na expressão do texto?

ANA TAGLIANETTI: A ópera utiliza a técnica lírica de canto, que consolida uma linha que privilegia o vibrato contínuo associado a uma impostação da voz bastante característica. 0 repertório operistico é bastante específico no que diz respeito à tipologia das vozes e à extensão vocal necessária. Da mesma forma, as demandas de resistência vocal costumam ser grandes. 0 cantor lírico costuma oferecer ao seu público seus malabarismos vocais particulares: suas notas mais graves ou mais agudas, suas coloraturas, todo o virtuosismo que é resultado de muito trabalho e que leva uma vida inteira para lapidar. Mas o objetivo é fazer música, "tocar" este instrumento, a voz, com a maior destreza possível, o que só é possivel com o desenvolvimento de uma técnica muito sólida. Assim como acontece na música erudita, a técnica vocal para o teatro musical tem o canto lírico em sua base. Entretanto, a técnica belting é a mais utilizada nesta manifestação artística.

0 belting consiste numa expressão vocal da "fala-cantada". Estamos falando o texto, mas uma fala que se expressa em frequências sonoras específicas, as notas musicais. A clareza do texto teatral está em primeiro plano. Aqui, o objetivo é fazer teatro, é contar uma história. 0 texto precisa ser entregue para o público com absoluta clareza. A técnica do belting foi desenvolvida com este propósito. É, na verdade, uma mistura de estilos que acabou resultando numa técnica muito apropriada para a linguagem teatral. Há também o objetivo de se mostrar virtuosismo, mas dentro de uma concepção bem diferente, em que a cena possui uma importância maior. Raramente a extensão vocal feminina, por exemplo, é usada nos seus extremos. Por outro lado, sopranos de graves abertos são essenciais para os grandes papéis dos musicais. Muitas vezes, no que diz respeito aos homens, se requer tenores com graves privilegiados, ou barítonos com agudos privilegiados para a execução das canções. Existe até uma expressão no meio musical que utiliza o belting que denomina esses cantores de "baritenors".

A técnica para a execução de música popular brasileira tem similaridades e diferenças em relação ao canto lírico e ao belting. Como no canto lírico, o cantor de MPB tem sua atenção voltada principalmente para a música, mas precisa de outros recursos musicais sofisticados, como a improvisação, que é praticamente inexistente no teatro musical e, mais ainda, na música erudita tradicional. Por outro lado, o cantor de MPB se aproxima mais do teatro musical pela preocupação com o entendimento das palavras, daí a restrição na utilização de vibrato e a moderação do virtuosismo.

$A M P B$, na maioria dos casos, não precisa que seus intérpretes usem uma grande extensão vocal, o que não quer dizer que eles não a possuam. A voz torna-se um instrumento do grupo, um instrumento que emite palavras, mas sempre com a música em primeiro plano. Não há cena teatral, ou quando há, é bastante sutil. Não é necessária uma grande projeção da voz, pois a MPB está associada ao recurso de amplificação. 0 cantor popular precisa saber usar bem o microfone e que deve ser tratado como um outro instrumento musical. Não é assim tão fácil usar corretamente o microfone. Novamente, isto não quer dizer que o cantor popular não saiba projetar a voz, mas não faz parte do estilo contemporâneo da música popular, especialmente a brasileira. Além das questões técnicas, é importante ressaltar que cada uma destas formas de utilização da voz - lírico, belting ou popular - possui estilos com características próprias. Bem próprias. Mas o que também não significa que não sejam intercambiáveis e possam trocar influências entre si. 
15 - FAUSTO BORÉM: É possivel para um cantor integrar as diferentes técnicas vocais?

ANA TAGLIANETTI: Quero esclarecer que, embora haja certo preconceito disseminado sobre estereótipos no meio musical - cantor lírico, cantor popular, cantor de musicais, é um mito dizer que o uso de uma técnica impossibilita o uso de outra. São como chaves liga-desliga, por mais que alguns discordem. São maneiras diferentes de usar o aparelho vocal. Não há razões que impeçam o ajuste do apareIho vocal de acordo com a necessidade. Como o instrumentista de cordas, o cantor pode iniciar, graduar e interromper o vibrato, como forma de expressão. Pode, também como o instrumentista de cordas que aproxima ou afasta o arco do espelho ou do cavalete, mudar o timbre e intensidade da voz, aumentando ou diminuindo o espaço oro-faringeo e laríngeo ou, mesmo, mudando o formato dos lábios. Mas, é claro, deve se conhecer os mecanismos para fazê-lo. Não adianta o cantor achar que pode cantar ópera se nunca estudou a técnica do canto operístico e a cultura da ópera! Para dominar qualquer uma destas técnicas, são necessários muitos anos de prática e estudo.

Por isso, o cantor que desenvolve uma técnica lírica consolida$\mathrm{da}$, que talvez seja a mais complexa, não terá dificuldades em transitar pelas outras técnicas, desde que resguarde algumas coisas. Tecnicamente falando, o canto lírico é o que apresenta maior dificuldade de execução. Assim, se o cantor quiser se aventurar pelas três técnicas, aconselho o estudo do canto lírico, antes de mais nada. É recomendável que o cantor de musicais possua técnica lírica, especialmente porque o repertório mais antigo de teatro musical exige essa versatilidade. A técnica lírica correta também proporciona uma grande saúde vocal e permite desenvolver uma resistência vocal impar, qualidade que o cantor de belting precisa para sobreviver a maratonas típicas da agenda dos musicais, como oito espetáculos consecutivos por semana, às vezes dois no mesmo dia.

16 - FAUSTO BORÉM: Quais são os desafios de adaptar uma partitura orquestral de um musical para a instrumentação disponível em uma escola de música na universidade pública brasileira?

DANIEL SOUZA: No Brasil, as condições oferecidas para se produzir um musical não são fáceis. Para que a sua produção não se torne inviável, é necessário que os organizadores adaptem os custos à realidade orçamentária que dispõe. Muitas vezes, não há dinheiro para fazer os espetáculos com música ao vivo. Assim, recorre-se a play backs prontos ou encomenda-se a sua gravação. Mas fazer o espetáculo com música ao vivo é sempre mais interessante para o público e para os cantores, pois se pode flexibilizar os andamentos, as intensidades, as articulações, a priorização das vozes etc. e levar em consideração a acústica de cada teatro ou sala. No caso de arranjos ou re-orquestração, a música deve ser analisada principalmente em relação às questões de equilibrio sonoro e timbres pretendidos na narrativa do espetáculo. Assim, qualquer adaptação da partitura deve considerar cuidadosamente as intenções da composição original.
17 - FAUSTO BORÉM: Ainda se observa bastante preconceito de ambas as partes, música erudita e a música popular, permeando seu espaço de convivência, seus valores estéticos, repertório, práticas de performance etc. Como se situa o musical dentro deste embate?

FERNANDO BUSTAMANTE: 0 teatro musical aparece nesse contexto como um mediador, já que torna possivel o diálogo entre a música erudita e a música popular dentro de uma mesma encenação.

18 - FAUSTO BORÉM: 0 Projeto Teatro Musical é um projeto que demanda uma grande dedicação artística por parte de todos os envolvidos: estar disponivel para centenas de horas de ensaio, aprender as falas, canções e coreografia dos colegas e cobri-los em emergências etc. Poderiam comentar sobre este ambiente de artistas ecléticos que se parece com uma grande familia, em que todos se ajudam mutuamente no sucesso e no fracasso de realizar um papel?

FERNANDO BUSTAMANTE: 0 artista de musicais tem que ser, obrigatoriamente, um profissional versátil. Saber cantar, dançar e interpretar minimamente são os principios básicos no perfil de quem deseja trabalhar um dia com o gênero. E o saber não exclui a necessidade de estudar diariamente para garantir a manutenção do corpo, voz e canto do ator. E por estarmos sujeitos a limitações e imprevistos físicos - como rouquidão, distensões etc. - voltamos àquela questão da necessidade de um coringa para todos os papéis. A gente acaba sempre voltando àquela máxima: "0 espetáculo não pode parar!"

19 - FAUSTO BORÉM: Falem sobre o show Uma noite na Broadway.

ANA TAGLIANETTI: Uma noite na Broadway é apenas o produto final, apresentado em público, de um processo de aprendizagem vivencial que procurou instrumentalizar os participantes nas técnicas necessárias para a performance em teatro musical. Corpo, movimento, técnica vocal, introdução ao teatro e vivência de montagem de espetáculo, tudo isso condensado em um só curso que resultou em uma montagem de highlights de grandes musicais da Broadway.

20 - FAUSTO BORÉM: Quais são os planos futuros para o Projeto Teatro Musical?

DANIEL SOUZA: Para 2010, o Projeto Teatro Musical deverá produzir o espetáculo Uma Noite na Broadway III Jazz!, que incluirá muitas das mais famosas músicas do repertório de jazz da Broadway. A coordenação do curso, oferecido como uma disciplina em nivel de graduação, estará centrada nas questões pedagógicas, buscando temáticas diferentes e aprendizados complementares para os alunos a cada novo espetáculo. Quanto a outros planos futuros, eles dependem de patrocínio e parcerias dentro e fora da UFMG, mas incluem principalmente seminários, masterclasses nacionais e internacionais com grandes nomes do teatro musical e da música em geral. 


\section{Notas}

1 A Casa de Artes OperÁria é o principal centro especializado no ensino e pesquisa da linguagem de musicais no Brasil. Foi criado por Ana Taglianetti em 2003. Alguns de seus trabalhos envolveram a preparação de mais de 30 espetáculos musicais, como A Palavra, e a formação de artistas do teatro musical como Alexandre Lima, Keila Bueno, Kátia Barros, Gianna Pagano, Julio Mancini, André Loddi, Luana Bichique, entre muitos outros.

2 Para uma discussão aprofundada sobre a substituição histórica do portamento pelo vibrato na música erudita veja LEECH-WILKINSON em Per Musi, n.15 (2007, p.7-25).

Ana Taglianetti é professora, cantora, atriz e diretora teatral especializada em ópera e teatro musical. Mestranda em Performance Vocal pela City University of New York e Bacharel pela Escola de Arte Dramática da ECA / USP. Em Nova lorque, especializou-se em Teatro Musical pela Lee Strasberg Theatre Institute, Regência de Ópera na Juilliard School of Music e Ópera na Mannes College of Music. Foi aluna de canto de Rosiris del Bianco e Leila Farah no Brasil e, em New York, foi aluna de Dodi Protero, Conrad Osborne, Trish McAffrey, Richard Barrett e Julian Kwok. Foi estagiária da Amato Opera, atuando com o maestro Tony Amato. Participou quatro vezes do programa VOICExperience com Sherrill Milnes, cantando no Players Club de New York e nos parques da Disney, na Flórida, e coordenou este programa no Brasil em 2006. Fundou a Casa de Artes OperÁria (www.operaria.com.br) em 2003, centro de formação para o teatro musical e ópera, na cidade de São Paulo, a partir da qual dirigiu mais de 30 espetáculos musicais. Sua montagem do musical A Palavra recebeu o prêmio de Melhor Espetáculo e indicações para os prêmios de Melhor Direção e Melhor lluminação do Festival de Limeira de 2007. Recebeu o prêmio de Atriz Revelação em 1987, ao ser dirigida por Gabriel Villela em A Capital Federal. Também foi dirigida por Silnei Siqueira, Luis Damasceno, Rodrigo Santiago, Beth Lopes, Joaquim Goulart e Carlos Alberto Soffredini. No Teatro Mvnicipal de São Paulo interpretou os papéis de Nedda (I Pagliacci, 1998), Leila (Pescadores de Pérolas, 1999) e Susanna (Bodas de Fígaro, 2000). No Brooklyn Center of Performing Arts, em Nova lorque, interpretou Mrs. Maurrant (Street Scene, 2000), Cherubino (Bodas de Figaro, 2000), Zozo (A Viúva Alegre, 2001), Cherubino (Three Little Pigs-2001). Na Amato Opera, em Nova Iorque, interpretou os papéis de Sacerdotisa (Aida, 1997), Musetta (La Bohème, 1998), Sally (O Morcego, 1999), Contessa Ceprano (Rigoletto, 1997), Giovanna (Rigoletto, 1997), Pagem (Rigoletto, 1997), Nedda (I Pagliacci, 1998). Com a Bronx Opera interpretou Toy Lamb Seller (Hugh the Drover, 1998) e Sally (O Morcego, 1999). Na Mannes College of Music interpretou Mrs. Pinkerton (Mme. Butterfly, 1997), Margherite (Mephistophele, 1998), Mimi(La Bohème, 1998). De 2002 a 2004 interpretou a Sra. Potts em A Bela e a Fera da Disney Theatrical Productions em São Paulo e integrou o elenco de Cole Porter: Ele Nunca Disse Que Me Amava. Em 2007, protagonizou e foi assistente de direção do musical José e Seu Manto Technicolor, dirigido por lacov Hillel. Desde 2008, coordena o Projeto Musicais na UFMG, em Belo Horizonte, onde já dirigiu duas edições do espetáculo Uma Noite Na Broadway. Versionou o texto para o português e dirigiu a ópera A Serva Patroa de Pergolesi, apresentada na abertura do I Festival de Teatro Musical de Belo Horizonte em 2009 e do I Festival de Música de Divinópolis, em 2010. Atualmente, interpreta o papel de Úrsula, na premiada montagem de $A$ Pequena Sereia, dirigida por Fernando Bustamante.

Daniel Souza é regente e diretor musical do Projeto Teatro Musical - Programa de Musicais na UFMG. Em 2008, foi um dos seis regentes selecionados para o 39॰ Festival de Inverno de Campos do Jordão, onde teve a oportunidade de estudar com os Maestros Kurt Masur (Alemanha) e Ronald Zolmann (Bélgica). Estudou também com Roberto Tibiriçá, Charles Roussin, Suely Lauar, lara Fricke Matte, Hoger Kolodziej (Alemanha), Osvaldo Ferreira (Portugal), Florin Totan (Romênia) e Lincoln Andrade e outros. É Bacharel em Regência pela Escola de Música da UFMG. Dedica-se ao estudo do teatro musical, piano, harpa, interpretação teatral, sapateado, dança de salão e canto (lírico e belting com a professora Ana Taglianetti). Coordenou diversos cursos e eventos de música erudita em Belo Horizonte que tiveram a participação de Neyde Thomas, Gilberto Tinetti e Fábio Zanon. Em 2007, criou, coordenou e dirigiu o Projeto Don Giovanni nas Ruas, com a versão "pocket" da ópera de Mozart. Em parceria com Ana Taglianetti, coordenou Uma Noite na Broadway, em 2008 e Uma Noite na Broadway ll - O Baú dos Sonhos em 2009. Fez a direção musical de A Pequena Sereia (com direção geral de Fernando Bustamante) em 2009 e A Serva Patroa: A Ópera ao alcance de todos (com direção geral de Ana Taglianetti) em 2009-2010. Regeu as Orquestra Acadêmica do Festival de Campos do Jordão, Orquestra de Câmara de Itaúna, Orquestra de Ópera e de Câmara das II, III IV Semanas da Música de Ouro Branco, Orquestra Sinfônica da Escola de Música da UFMG, Orquestra de Musicais da UFMG e a Orquestra Drammato. 
Fernando Bustamante é Licenciado em Artes Cênicas pela UFMG. Ator, produtor, diretor e coreógrafo profissional, trabalhou em cerca de 30 peças de teatro e musicais desde 1995, muitos das quais foram premiadas. Em 2008, dirigiu e produziu o espetáculo A Arca de Vinicius, que recebeu os prêmios SESC/SATED de Melhor Espetáculo, Melhor Diretor e USIMINAS/ SINPARC de Maior público, Melhor Espetáculo e Melhor Iluminação. Em 2005, produziu o musical Lampiãozinho e Maria Bonitinha, que recebeu os prêmios SESC/SATED de Melhor Espetáculo, Melhor Ator, Melhor Atriz, Melhor Ator Coadjuvante, Melhor Atriz Coadjuvante e os Prêmios USIMINAS/SINPARC de Melhor Espetáculo, Melhor Texto, Ator Revelação, Melhor Iluminação, Melhor Figurino e Melhor Trilha Sonora. No mesmo ano, foi indicado como Melhor Preparador Corporal com a peça Sem Vergonhas no Prêmio SESC/SATED. Em 2004, atuou e produziu Os Saltimbancos, que recebeu o prêmio de Melhor Espetáculo Infantil e Melhor Atuação no $1^{\circ}$ Festival Nacional de Teatro de Juiz de Fora. Em 2004, recebeu o prêmio de Melhor Ator na peça O Menino Maluquinho, concedido pelo SESC/SATED. Em 2003, dirigiu e produziu A Pequena Sereia, recebendo os Prêmios SINPARC e SESC/SATED de Melhor Espetáculo, Melhor Atriz, Melhor Ator Coadjuvante, Melhor Cenário e Maior Público. Em 2003, foi indicado à Melhor Coreografia do Prêmio SATED com a peça Sonho Dourado. Em 2001, recebeu 0 Prêmio de Melhor Ator Coadjuvante pela AMPARC com a peça O Mistério da Princesa Feiurinha. Em 2000, foi indicado como Melhor Ator Coadjuvante com a peça Com Jeito Vai pela AMPARC e SESC/SATED.

Fausto Borém é Professor Titular da Escola de Música da Universidade Federal de Minas Gerais (UFMG), onde criou o Mestrado em Música e a Revista Per Musi. É pesquisador do CNPq desde 1994 e seus resultados de pesquisa incluem um livro, três capítulos de livro, dezenas de artigos sobre práticas de performance e suas interfaces (composição, análise, musicologia, etnomusicologia e educação musical) em periódicos nacionais e internacionais, dezenas de edições de partituras e apresentação de recitais nos principais eventos nacionais e internacionais do contrabaixo. Recebeu diversos prêmios no Brasil e no exterior como solista, teórico, compositor e professor. Acompanhou músicos eruditos como Yo-Yo Ma, Midori, Menahen Pressler, Yoel Levi, Fábio Mechetti, Luiz Otávio Santos, Arnaldo Cohen, Antônio Menezes e músicos populares como Hermeto Pascoal, Egberto Gismonti, Henry Mancini, Bill Mays, Kristin Korb, Grupo UAKTI, Toninho Horta, Juarez Moreira, Tavinho Moura, Roberto Corrêa, Maurício Tizumba e Túlio Mourão. Suas gravações incluem o CD Brazilian Music for the Double Bass, o CD e DVD O Aleph de Fabiano Araújo Costa, os CDs da Orquestra Barroca do Festival Internacional de Juiz de Fora de 2005 a 2009 (com Luiz Otávio Santos), a Suite for Flute and Jazz Piano de Claude Bolling (com Maurício Freire, Tânia Mara e Eduardo Campos) e No Sertão (com o violista Roberto Corrêa) e Cidades Invisíveis (com o saxofonista Daniel d'Olivier) 